\title{
Control of invasive American bullfrog Lithobates catesbeianus in small shallow water bodies
}

\author{
Gerald Louette $\cdot$ Sander Devisscher • Tim Adriaens
}

Received: 26 March 2012 /Revised: 5 July 2012 / Accepted: 17 July 2012 /Published online: 17 August 2012

(C) The Author(s) 2012. This article is published with open access at Springerlink.com

\begin{abstract}
Setting up cost-efficient control programs for alien invasive species requires the development of adequate removal methods in combination with insights in population size and dynamics. American bullfrog Lithobates catesbeia$n u s$ is an alien invasive species, which is suspected to cause substantial ecological damage around the globe. However, control of bullfrog populations is difficult, as no conclusive management measures have yet been determined. We investigated how double fyke nets could contribute to bullfrog management by assessing the tadpole population size in 10 permanent small shallow water bodies. Two population size estimate methods were applied, being the catch-depletion and mark-recapture method. Catchability of bullfrog tadpoles proved to be very consistent over ponds and methods, with one catch per unit of effort (one double fyke net for $24 \mathrm{~h}$ ) retaining on average $6 \%$ of the tadpole population. Population density varied considerably among ponds, ranging from 950 to 120,804 larger tadpole individuals/ha. Using these insights in developing a cost-efficient eradication program for the species, we projected the number of catch efforts needed to reduce tadpole numbers to a threshold that more than likely affects final bullfrog population size. Predictions indicated that for the specified thresholds the use of eight double fyke nets at a time is most cost-efficient in high abundance populations, while using five double fyke nets seems most suitable in low abundance populations. What the exact threshold number of remaining tadpole individuals should be is uncertain, but forecasts demonstrate that only half of the budget would be needed
\end{abstract}

Communicated by C. Gortazar

G. Louette $(\square) \cdot$ S. Devisscher $\cdot$ T. Adriaens

Research Institute for Nature and Forest,

Kliniekstraat 25,

B-1070, Brussels, Belgium

e-mail: gerald.louette@inbo.be when aiming at a drop to fewer than 100 remaining tadpoles than when a decrease to fewer than 10 remaining tadpoles is pursued. Given the fairly limited cost of bullfrog management with double fyke nets, however, it may be worthwhile to fully reduce the tadpole population.

Keywords Catchability · Catch-depletion · Double fyke nets $\cdot$ Management $\cdot$ Mark-recapture $\cdot$ Rana catesbeiana

\section{Introduction}

Alien invasive species are generally accepted as one of the most significant threats to biodiversity (Mooney and Hobbs 2000). Their harmful influence on native biota necessitates the establishment of management methods to control their expanding populations (Hauser and McCarthy 2009). To develop such management programs, insights into population size are key prerequisite (Smith et al. 2005). Information on population size, population dynamics, and (the development of) adequate removal methods enables the design of cost-efficient management programs to combat alien invasive or pest species.

American bullfrog Lithobates catesbeianus, originally occurring in Northeast America, is an alien invasive species and has been introduced for aquaculture purposes over large parts of the globe during the last century (Kraus 2009). However, escapes took place and wild populations arose in these new environments, causing substantial ecological damage (Adams and Pearl 2007). The species is believed to predate on, and compete with indigenous amphibians (Kupferberg 1997; Pearl et al. 2004; Johnson et al. 2011), as well as transmit pathogens from which they themselves experience little inconvenience (Garner et al. 2006; Sharifian-Fard et al. 2011; Martel et al. 2012). Because of this array of negative impacts on other biota, the species is 
considered as one of the world's top 100 alien invasive species (Lowe et al. 2000), for which immediate and drastic management measures are necessary (Doubledee et al. 2003; Govindarajulu et al. 2005).

However, control and, by extension, eradication of introduced bullfrog populations is difficult, as no conclusive management measures have yet been delineated (Adams and Pearl 2007). A range of methods are used, including habitat alteration (Maret et al. 2006), shooting adults (Berroneau et al. 2008), netting (D'Amore et al. 2009), trapping (Snow and Witmer 2011), and frightening tadpoles from their optimal habitat (Wassersug 1997). The choice of methods used at specific locations not only depends on legislative frameworks, available budgets, timeframe for operating, situational context, but also on public opinion and local animal welfare issues (Bremner and Park 2007; Ficetola et al. 2007). Population demographic models indicate that only removing a part of the tadpole population may lead to faster tadpole developmental rates and higher tadpole and post-metamorphic survival due to decreased density-dependent competition (Govindarajulu et al. 2005). Removal of adults on the other hand may lead to a higher survival of early metamorphic stages through reduced cannibalism. This makes bullfrog control a difficult task for managers.

The European Union recognizes the issue of alien invasive species and is currently taking positions through policy letters (EC 2008; EC 2011) and the funding of programs for actions in the field, such as Life + and Interreg (Scalera 2010). For invasive bullfrogs, a specific eradication program was recently initiated in the framework of the Interreg project "Fighting alien invasive species along the DutchBelgian border (northwest Europe)" (INVEXO-Invasieve exoten in Vlaanderen en Zuid-Nederland, Interreg IVaVLANED-2.31). In this region, bullfrogs are present in several small and isolated populations, where they established after deliberate releases in garden ornamental ponds or escapes from fish aquaculture ponds where they occurred as stowaways (Jooris 2005).

The general objective of this study was to investigate if bullfrog populations can be decimated or eradicated. As preliminary research indicated that double fyke nets are acceptable with regard to both public opinion, animal welfare, and cost efficiency, they were considered a promising method (Detaint and Coïc 2006; Berroneau et al. 2008; Louette 2012). More specifically, the current study had the specific objectives of: (1) defining the catchability of bullfrogs, using double fyke nets in small shallow ponds; (2) estimating population size and investigating the accuracy of two different methods (catch-depletion and mark-recapture); and (3) verifying if a single catch per unit of effort (CPUE) can be used as a good proxy for the actual population size. Finally, (4) we attempted to predict how isolated bullfrog populations in small shallow ponds can be impacted with sustained and intensive depletion of individuals using double fyke nets.

\section{Methods}

Bullfrog populations were investigated in 10 permanent water bodies (Tables 1 and 2). Three water bodies were located in Hoogstraten (N 51 ${ }^{\circ} 28^{\prime}$ E $04^{\circ} 45^{\prime}$, northcentral Belgium), three in Arendonk (N 51 ${ }^{\circ} 19^{\prime}$ E $05^{\circ} 06^{\prime}$, northeast Belgium), and four water bodies were situated in Balen (N $51^{\circ} 09^{\prime}$ E $05^{\circ} 08^{\prime}$, northeast Belgium). All water bodies were small shallow fish ponds, with an average surface area of $1,500 \mathrm{~m}^{2}$ and a maximum depth of $150 \mathrm{~cm}$. The ponds contained no or little submerged macrophytes, but often a small belt of reed Phragmites australis and soft rush Juncus effusus along the shoreline were present. The fish community frequently contained large numbers of non-native species (e.g., brown bullhead Ameiurus nebulosus, pumpkinseed Lepomis gibbosus, and topmouth gudgeon Pseudorasbora parva), supplemented with native planktivorous (e.g., roach Rutilus rutilus and rudd Scardinius erythrophthalmus) and benthivorous species (e.g., Prussian carp Carassius gibelio, common carp Cyprinus carpio), while piscivorous species (e.g., pike Esox lucius and perch Perca fluviatilis) were mostly absent. Bullfrogs have been present in the study ponds for a decade (Jooris 2005), potentially outcompeting the ponds' currently rare indigenous edible frog species complex (Pelophylax spp.), common frog Rana temporaria, and common toad Bufo bufo but probably also causing pathogen transmission to other native anuran and caudatan species.

Bullfrog tadpoles, metamorphs (juvenile bullfrogs that just underwent metamorphosis), and adults were caught using double fyke nets (height and width of the first hoop 80 and $90 \mathrm{~cm}$, respectively, three narrowing funnels in each fyke, leader net $7 \mathrm{~m}$, and mesh size $8 \mathrm{~mm}$ ). This sampling gear is considered highly appropriate for use in the type of ponds under study, as it is less expensive, durable, userfriendly, and generates relatively large catches for actively swimming species (Louette and Declerck 2006). Furthermore, fyke nets are ethical as bycatch can be released into the water body in good condition. Drowning of adults was prevented by placing a closed empty plastic bottle in the last fyke compartment, ensuring that frogs were able to surface and take air.

Population density was estimated using the catchdepletion and mark-recapture methods. Both methods require the assumptions of closed populations (no immigration and emigration, no recruitment or mortality) during the sampling period and an equal catchability of individuals in the population (Maceina et al. 1995; Lampo and Bayliss 


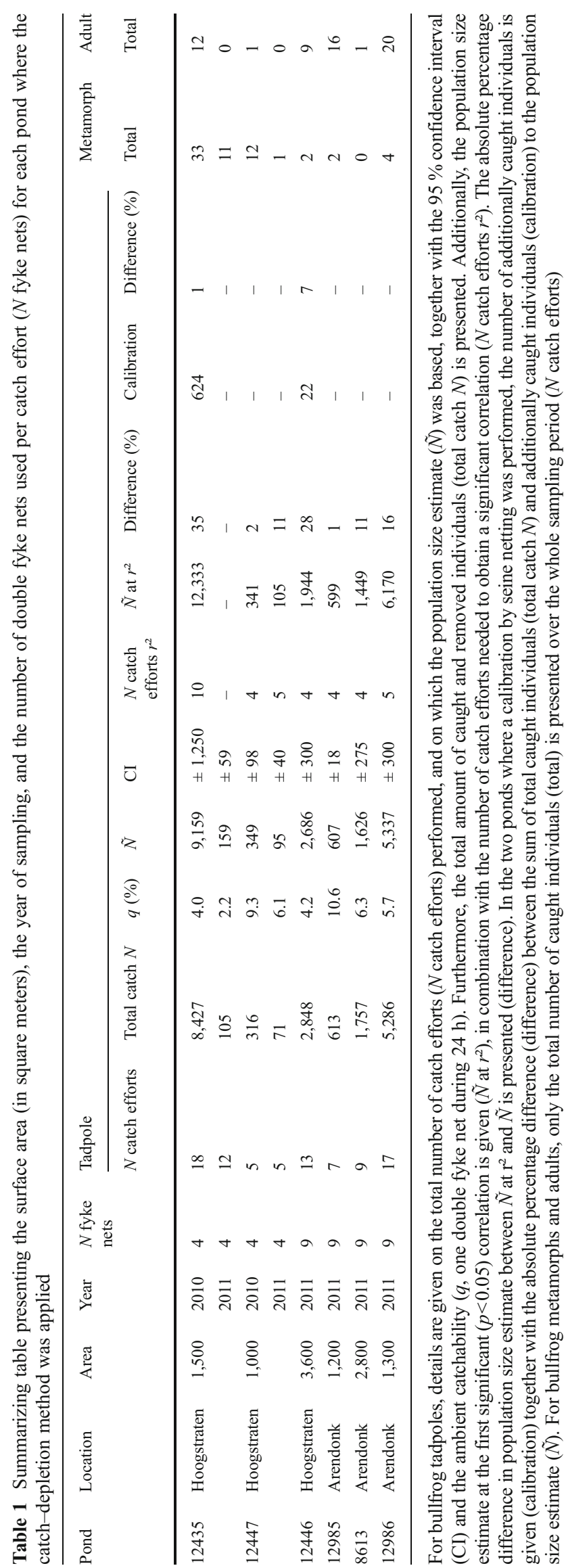

1996; Odenkirk and Smith 2005). Since these assumptions were unlikely to be met for metamorphs and adults, population estimates were restricted to tadpoles in each pond.

In six water bodies (Hoogstraten and Arendonk), we estimated bullfrog tadpole population density (only tadpole individuals larger than $6 \mathrm{~cm}$ were retained by the double fyke nets) by the catch-depletion method (period of MaySeptember for two ponds in 2010 and for six ponds in 2011, including the two ponds sampled in 2010). In these ponds, a number of double fyke nets were set (parallel and two meters out from the shore) for $24 \mathrm{~h}$, covering all sides of the water body. A minimum of three catch efforts of equal magnitude (see Table 1 for the number of double fyke nets per catch effort) were performed. After every catch effort, all captured individuals were removed from the population. An estimate can be made of the population size through the decrease of the CPUE (average number of individuals in one double fyke net for $24 \mathrm{~h}$ ) over time (subsequent catch efforts). Bullfrog tadpoles captured were euthanized by overdosing with benzocaïne $(0.4 \mathrm{~g} / 1$ water). Bycatch of bullfrog metamorphs and adults were counted and underwent the same treatment. Bycatch of fish were released back in the pond in good condition. A population estimate of tadpoles was obtained using the Leslie method (Krebs 1989):

$\widetilde{N}=K+\frac{Y}{q}$

and

$q=\frac{-\sum_{i=1}^{s} Y_{i}\left(K_{i}-K\right)}{\sum_{i=1}^{s}\left(K_{i}-K\right)^{2}}$

with $\tilde{N}=$ estimated size of the population at the start of sampling, $K_{i}=$ accumulation of catch from start to day $i$, $K=$ average value of $K_{i}, Y_{i}=$ catch per unit of effort, $Y=$ average value of $Y_{i}$, and $q=$ catchability.

The population size can also be estimated by linear regression between the cumulative catch $\left(K_{i}\right)$ and the catch per unit of effort $\left(Y_{i}\right)$. Population size before any sampling is then the intercept of the regression line on the $X$-axis (i.e., when no individuals are removed from the population). Next to the population size estimate made with data of all catch efforts, we verified from which catch effort onwards the correlation between $K_{i}$ and $Y_{i}$ became significant and how this estimate differed. Furthermore, an estimate of the catchability of individuals is given by the absolute value of the slope $\left(b_{1}\right)$ of the regression line, representing the chance that an individual will be captured with one unit of effort (in this case, one double fyke net during $24 \mathrm{~h}$ ).

To determine the accuracy of population size estimates following the catch-depletion method, we performed a calibration in two ponds (12435 and 12446) (Rider et al. 
Table 2 For each pond where the mark-recapture method was used, the surface area (in square meters), the year of sampling and the number of double fyke nets used per catch effort ( $N$ fyke nets) is presented

\begin{tabular}{|c|c|c|c|c|c|c|c|c|c|c|c|c|c|c|c|}
\hline \multirow[t]{2}{*}{ Pond } & \multirow[t]{2}{*}{ Location } & \multirow[t]{2}{*}{ Area } & \multirow[t]{2}{*}{ Year } & \multirow[t]{2}{*}{$\mathrm{N}$ fyke nets } & \multicolumn{7}{|c|}{ Tadpole } & \multicolumn{2}{|c|}{ Metamorph } & \multicolumn{2}{|l|}{ Adult } \\
\hline & & & & & $M$ & $R$ & $\mathrm{RC}(\%)$ & $\tilde{N}$ & CI & CPUE & $q(\%)$ & CPUE & Total & CPUE & Total \\
\hline 13356 & Balen & 1,600 & 2010 & 3 & 300 & 9 & 3.1 & 19,329 & $\pm 14,803$ & 717 & 3.7 & 0 & 0 & 0.3 & 1 \\
\hline 13357 & Balen & 1,700 & 2010 & 3 & 218 & 10 & 4.7 & 1,955 & \pm 996 & 83 & 4.2 & 0 & 0 & 1.0 & 6 \\
\hline 13358 & Balen & 1,100 & 2010 & 3 & 388 & 7 & 1.9 & 2,998 & $\pm 1,592$ & 112 & 3.7 & 0 & 0 & 0.0 & 0 \\
\hline 13359 & Balen & 1,100 & 2010 & 3 & 230 & 22 & 9.4 & 665 & \pm 148 & 70 & 10.5 & 0 & 0 & 0.2 & 1 \\
\hline
\end{tabular}

Furthermore, details on the number of bullfrog tadpoles that were marked on day $i(M)$ and number of recaptured marked individuals on day $i+1(R)$ are given, as well as the derived recapture efficiency (RC or catchability) of this segment of the population. Using the ratio between the estimated population size $(\tilde{N})$ and the average catch per unit of effort (CPUE), a second catchability value was determined $(q)$. In the case of bullfrog metamorphs and adults, the average catch per unit of effort (CPUE) is presented, as well as the total number of unique caught individuals (total) over the 2-day sampling period

1994; Penczak et al. 2003). In September, after the sampling campaign, both ponds underwent multiple (three to five) thorough passings with a seine net $(25 \mathrm{~m}$ long, $2 \mathrm{~m}$ high, mesh size $8 \mathrm{~mm}$ ). The number of tadpoles (individuals larger than $6 \mathrm{~cm}$ ) still present was determined, after which they were euthanized as described before. In one of the two ponds (12345), prior to seine netting, the water was pumped out to a level of $30 \mathrm{~cm}$ with a self-priming wastewater pump. To prevent tadpoles from being pumped together with the water, the suction head of the pump was covered with a filter net (mesh size $8 \mathrm{~mm}$ ). The sum of additionally caught individuals by seine netting and the total number of caught individuals during the catch efforts with double fyke nets was then compared with the population size estimate.

The mark-recapture method was used to estimate population size in four ponds in Balen (May 2010). During a first sampling effort, a number of individuals were marked (day $i$ : three double fyke nets of which one was placed in the center of the pond, and two parallel and $2 \mathrm{~m}$ out from the two opposite shores, $24 \mathrm{~h}$ ). Marking of individuals was conducted by a subcutaneous high-pressure injection of biological pigment on the tail tip of tadpoles (Jet Injector, Schuco). Individuals captured and marked were released in good condition in all parts of the pond. At the second sampling effort (day $i+1$ ), the proportion of marked and unmarked individuals relative to the total number of marked individuals on day $i$ was determined. An estimate of the population was obtained, using the Petersen formula (Krebs 1989):

$\widetilde{N}=\frac{C M}{R}$

with $\tilde{N}=$ estimated size of the population, $M=$ number of individuals that are marked at the first catch, $R=$ number of individuals at the second catch that have a mark, and $C=$ total number of individuals at the second catch.
In order to predict the time needed and the monetary cost involved in depleting a bullfrog tadpole population in a given water body (assuming no further reproduction), we forecasted tadpole population size at the end of the summer using various catch intensities. Three different intensity levels of removal were investigated for two contrasting starting abundances: a low population abundance of 1,000 tadpoles and a high population abundance of 5,000 tadpoles (corresponding with the actual density range in the small shallow ponds, see "Results"). The first intensity level involved the use of two double fyke nets with a total cost of $138 €$ per catch effort, covering staff time of two collaborators (transport to a given pond and actual field work) and depreciation of equipment. The second (intermediate effort) and third (maximal achievable effort per day) intensities were, respectively, five $(308 €)$ and eight double fyke nets $(478 €)$. We postulated the depletion action, leading to a certain percentage of the population removed according to the three intensities, to be performed at the beginning of the summer, where after each catch effort the number of remaining tadpoles at the end of the summer is projected, taking into account a seasonal survival of $56 \%$ (Provenzano and Boone 2009). We thereby focused on the number of catch efforts (and thus cumulative cost over catch efforts) required to reach an arbitrary threshold value of fewer than 100 or 10 remaining tadpoles at the end of the summer under different catch intensities.

\section{Results}

Catchability of bullfrog tadpoles by double fyke nets in small shallow ponds proved to be very consistent (Tables 1 and 2). Over the 10 water bodies, one CPUE (double fyke net/24 h) caught on average $6 \%$ (SE 1) of the bullfrog tadpole population, with a range of $2-11 \%$. Moreover, the catchability seemed to be reproducible for 
density estimates obtained with both the catch-depletion and mark-recapture method, with average catchability values of 6 and $5 \%$, respectively. In ponds where the mark-recapture was applied, the catchability assessed by the proportion of the average CPUE on the estimated population size and the catchability based on recapture efficiency (the proportion of the caught marked individuals at day $i+1$ in an average CPUE on the total amount of individuals marked on day $i$ ) were comparable in each pond, with on average $6 \%$ for catchability and $5 \%$ for recapture efficiency (Table 2 ).

Population size estimates of bullfrog tadpoles by the catch-depletion method were significant from four catch efforts onwards (median value), using on average five double fyke nets per catch effort (Table 1). The estimated population size at the moment that the relationship between the cumulative (removed) catch until a given catch effort and CPUE of each catch effort became significant (Fig. 1) deviated on average $5 \%$ from the final population size estimate (calculated after 11 catch efforts, median value). For the two ponds where a calibration was made to determine population size estimate efficiency, 1-7\% divergence was observed between the final population size estimate and the sum of caught individuals in the sampling period with double fyke nets and seine nets, implying robustness of population estimates by the catch-depletion method.

The population density of bullfrog tadpoles varied considerably among ponds (Fig. 2). The average was 24,296 individuals/ha (SE 10,286), with a range of 950-120,804. As no estimates of population size could be made for metamorphs or adults, we present the total number of caught individuals over the entire sampling campaign for both age classes (Tables 1 and 2), ranging from 0 to 33 individuals for metamorphs (median value of three individuals for the ponds where the catch-depletion method was applied) and 0-20 individuals for adults (median value of five individuals for the ponds where the catch-depletion method was applied).

The relationship between the CPUE and the estimated population size of bullfrog tadpoles in small shallow ponds, as well as between the CPUE and the estimated population density, was highly significant: $r^{2}=0.98, p<0.001 ; r^{2}=0.95$, $p<0.001$, respectively (Fig. 3 ). The number of caught individuals in one CPUE seems therefore a good estimate of the actual population size and density in small shallow water bodies.

Following the catchability of around $6 \%$ for bullfrog tadpoles with one double fyke net per $24 \mathrm{~h}$, it is important to assess what scenario is most efficient in depleting tadpole populations in small shallow ponds (Fig. 4). For instance, to achieve fewer than 10 remaining individuals at the end of the summer in high (5,000 individuals) abundance tadpole populations, the use of eight double fyke nets at a time seems most cost-efficient. Eight double fyke nets will remove approximately $39 \%\left(1-(1-q)^{\wedge}\right.$ number of double fyke nets, being thus $\left.1-(1-0.06)^{\wedge} 8\right)$ of the population with each catch effort, which implies a total cost of $5,736 €(12$ catch efforts of $478 €$ ) required to reach this threshold. However, for low (1,000 individuals) abundance tadpole populations, the use of five double fyke nets (removal of approximately $27 \%$ of the population with each catch effort) seems most cost efficient, as only $4,004 €$ (13 catch efforts of $308 €$ ) is needed compared to $4,302 €$ when using eight double fyke nets (nine catch efforts of $478 €$ ). In contrast, using only two double fyke nets at each catch effort (approximately $12 \%$ removal of the ambient population), a cost of 4,416 $€$ (32 catch efforts of $138 €$ ) would be needed for low abundance populations and 6,210 $€$ (45 catch efforts of $138 €)$ for high abundance populations. When setting the target higher (fewer than 100 remaining tadpoles in the population), using eight double fyke nets equates to a cost of $1,912 €$ in low abundance (only slightly higher than $1,848 €$ when using five double fyke nets) and 3,346€ in high abundance populations. This cost is 44 and $58 \%$, respectively, of the cost for achieving the threshold of 10 remaining individuals.

\section{Discussion}

Insights in the population size of alien invasive species are crucial with regard to their management (Smith et al. 2005). Such information, coupled with an effective capture gear, can help to direct a cost-efficient approach in alien invasive species management. For instance, intensity per catch effort, number of catch efforts, timespan, and time of year may all be adjusted to achieve a population size below a certain threshold level. When repeated over multiple years, while simultaneously preventing new introductions, reproduction, and immigration, populations can be depleted until they go extinct. For bullfrogs, double fyke nets appeared to be very effective in catching tadpoles in small shallow ponds. A single CPUE attains around $6 \%$ of the ambient tadpole population, a number found to be very consistent over ponds and over different population size estimate methods (catchdepletion and mark-recapture). Obviously, some deviations from this average catchability occur and can arise from weather conditions and specific pond features (e.g., morphology, water temperature, spatial structure, macrophytes, and presence of specific predators). The observed catchability percentage is promising with respect to an almost full eradication of tadpoles, and hence subsequent negative effects on the number of forthcoming metamorphs and adults. Moreover, performing an exploratory CPUE in unexamined ponds may provide a good and swift proxy of the actual population size. This provides indicative data on the magnitude of impact bullfrogs can 

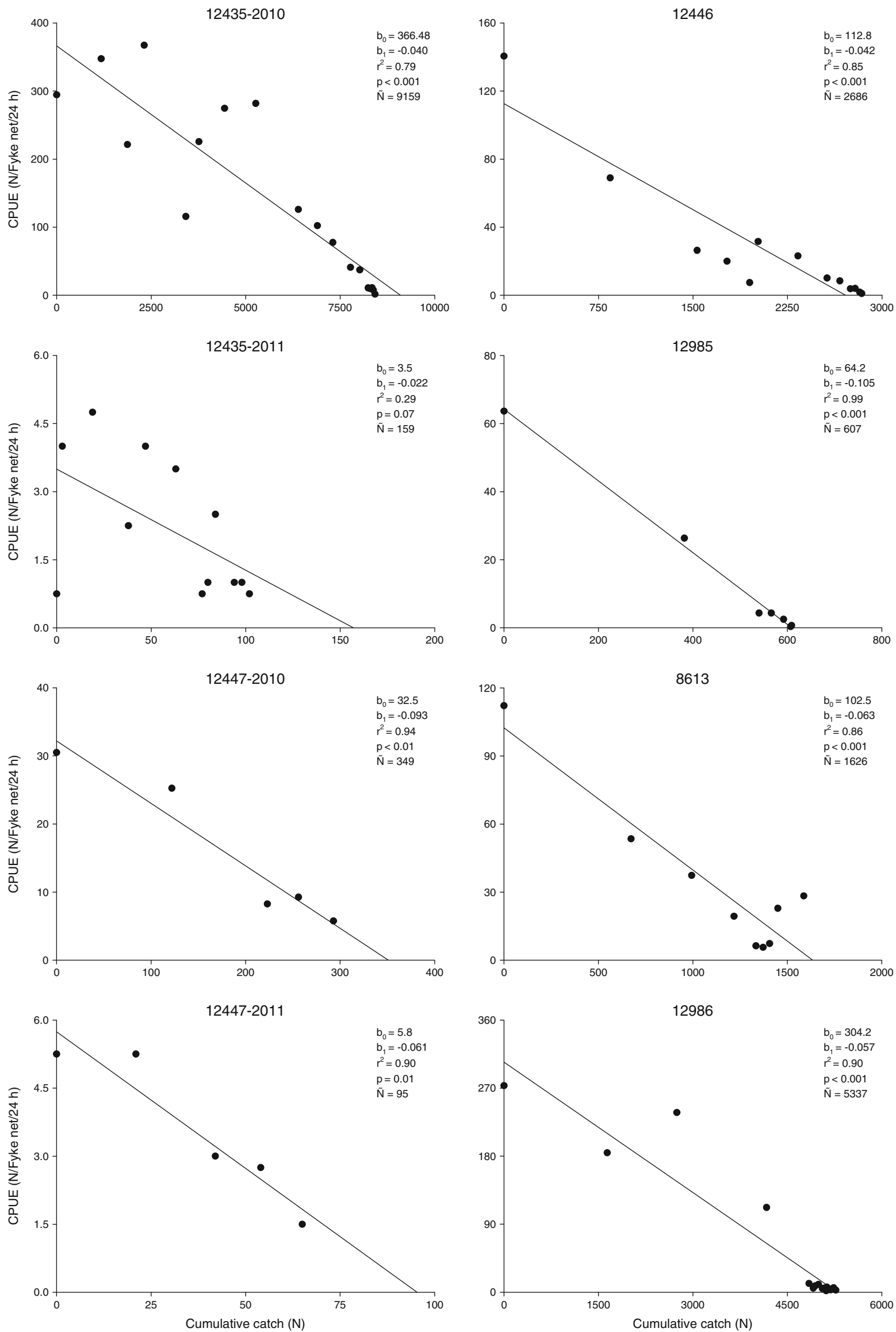
Fig. 1 Negative linear relationship between the cumulative (removed) catch of bullfrog tadpoles and the catch per unit of effort (CPUE) in six water bodies where we applied the catch-depletion method. The $X$ intercept of the regression line gives the initial estimated population size; the absolute value of the slope $\left(b_{1}\right)$ represents the catchability of individuals at the given unit of effort. For two ponds, the technique was applied in both 2010 and 2011

have on other biota and is also vital in supporting decisions for possible further management actions.

Overall, population size estimates using the catchdepletion method were quite robust from the fourth catch effort onwards, showing only for some ponds an underestimate of the final number of caught individuals. In these cases, this may be explained by a relatively long timespan between start and end of the removal campaign. Consequently, no fully closed population can then be assumed, as small tadpoles might have reached the size needed to be retained by the nets. The actual tadpole population density varied considerably among ponds and may be due to differences in habitat characteristics, such as food availability, structural elements, and predation intensity by invertebrates and vertebrates (Adams et al. 2003; Louette 2012). However, estimated numbers are in line with the range reported in earlier studies (Cecil and Just 1979; Govindarajulu et al. 2006). Also, previous management efforts can drastically influence (i.e., decrease) population size, as tadpole numbers in the two ponds (12435 and 12447) that underwent a trapping treatment during two consecutive years varied around 2 and $27 \%$, respectively, of the initial population size.

Cost efficiency is crucial in eradication programs and a good estimate of this is an essential step in conservation triage, e.g., the choice between habitat restoration or pest eradication (Bottrill et al. 2008). We projected the number of catch efforts needed to reduce two contrasting tadpole population sizes to a threshold that more than likely affects final bullfrog population size. In the worked examples, we defined a maximum threshold of less than 100 remaining tadpole individuals after the completing of an eradication action. Although such an effort requires only around half of the budget of actions aiming at a maximum of less than 10 remaining individuals, the number of surviving metamorphs will consequently be around a tenfold the following years. Assuming a yearly survival rate of $13 \%$ from metamorph to adult and $32 \%$ from adult to adult (Govindarajulu et al. 2005), with 2 years before reaching adulthood after metamorphosis (Govindarajulu et al. 2006), about four adults will arise from a threshold of 100 surviving tadpoles. Actions aiming at a threshold value of 10 tadpoles would therefore generate an even greater probability of preventing a single individual from reaching adulthood. What the exact threshold value should be is uncertain, as the survival rate of tadpoles is contextual. For instance, inter- and intraspecific competition for resources (Werner 1994), predation by macroinvertebrates and to a lesser extent carnivorous fish (Cecil and Just 1979; Adams et al. 2003; Szuroczki and Richardson 2011), and cannibalism by bullfrog adults (Govindarajulu et al. 2005) may all influence survival rate
Fig. 2 Estimated population density $(\tilde{N} / \mathrm{ha})$ of bullfrog tadpoles in the 10 investigated water bodies. For two ponds, an estimate was made in both 2010 and 2011

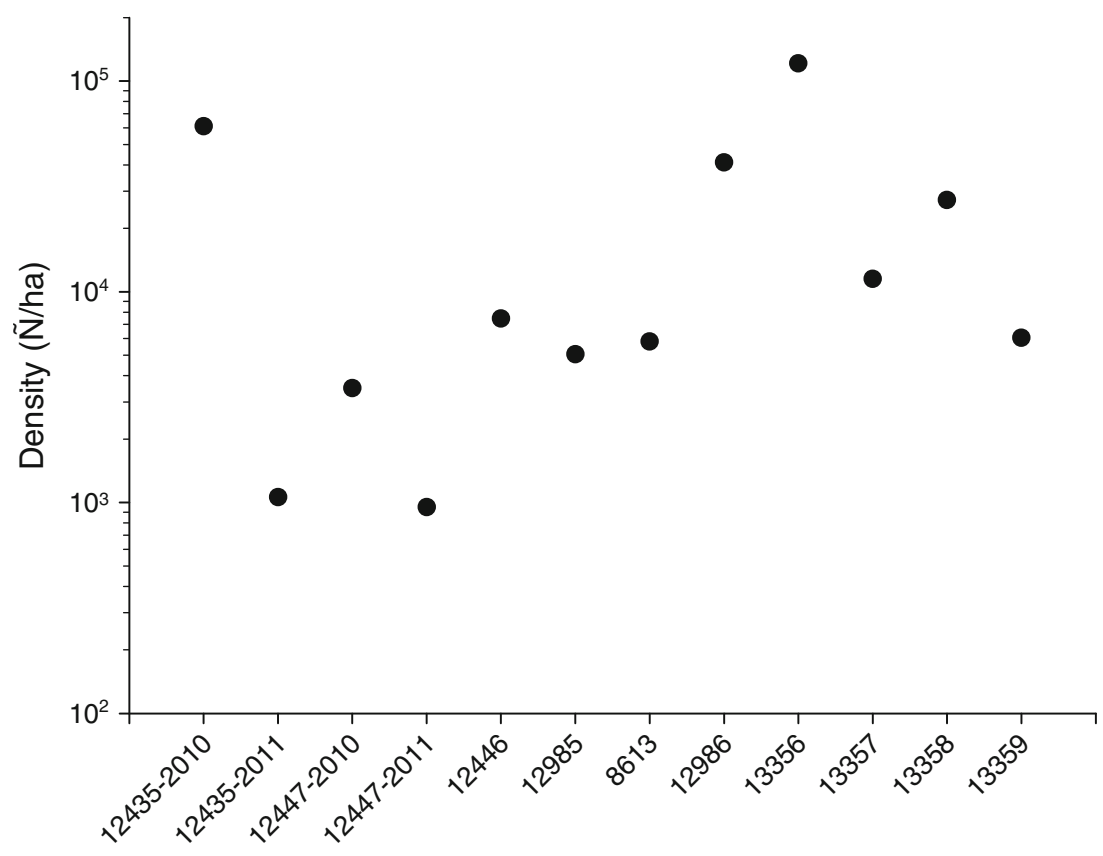

Pond number 
Fig. 3 Positive linear relationship between the catch per unit of effort (CPUE) and the estimated population size $(\tilde{N})$ of bullfrog tadpoles in small shallow ponds (upper panel) and between the CPUE and the estimated population density (N/ha) (lower panel). Data entry points included six water bodies where the catch-depletion method was applied (closed dots) and four water bodies where the mark-recapture method was used (open dots). CPUE data from water bodies where the catch-depletion method was performed concerned those of the first catch effort (when no tadpole individuals were yet removed from the population)
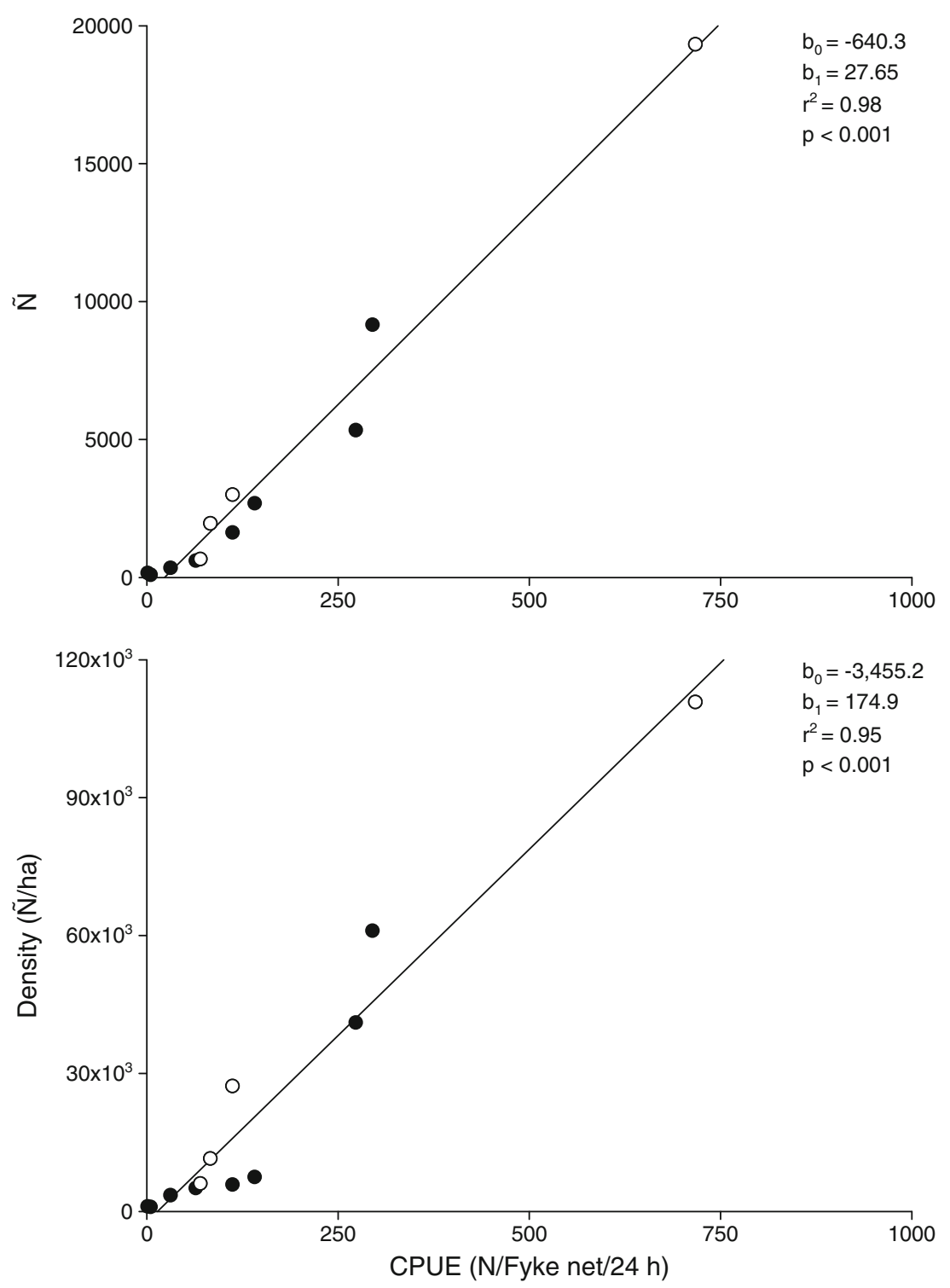

of tadpoles. However, given the rather low projected costs (around 2,500 to 5,000 $€$ per pond and per season), actions should be aimed at reaching a minimal number of individuals reaching the metamorph and adult stages. Indeed, these life stages can disperse to other suitable sites, potentially transfer pathogens, and subsequently reproduce, starting the cycle all over again. In order to drastically reduce the population, a sustained effort of catching the remaining tadpoles should be accomplished, combined with preventing reproduction (retention of adults in the breeding water bodies or egg clump removal) the following years.

Earlier studies pointed to the culling of metamorphs in fall as the most cost-efficient method for eradication of bullfrog populations (Govindarajulu et al. 2005). Although amphibian population growth rate is more sensitive to the survival rate of metamorphs than tadpoles (Biek et al. 2002), our study demonstrates that with the applied capture gear, considerable amounts of tadpoles can be removed with rather limited budgets. Double fyke nets of the model dimensions we used, thus seem an appropriate choice for controlling or eradicating bullfrog populations in the type of water body (permanent, small and shallow) considered. Moreover, it is easy to implement compared to other methods, such as draining which is not always possible or seining that in case of abundant growth of macrophytes or irregular pond bottoms is not efficient. Furthermore, the costs of eliminating a considerable proportion of tadpoles, metamorphs, and adults by other, often more controversial eradication methods (terrestrial trapping, shooting, fencing, draining, netting), seem to be much higher (Reinhardt et al. 2003; Moissonnier et al. 2007; Foster and Banks unpublished 
Fig. 4 Relationship between the cumulative cost of each catch effort and the associated predicted population size of bullfrog tadpoles at the end of the summer (remaining part in population) after depletion with various catch intensities. Catch intensities involve two (closed circles), five (open circles), and eight (closed triangles) double fyke nets for each catch effort at two starting abundances (upper panel 1,000 tadpoles, lower panel 5,000 tadpoles). Note that the $Y$-axis is displayed in a logarithmic scale and that the non-transformed relationship actually exhibits an exponential decay. The dotted lines indicate the boundary of fewer than 100 and 10 remaining individuals in the simulated populations
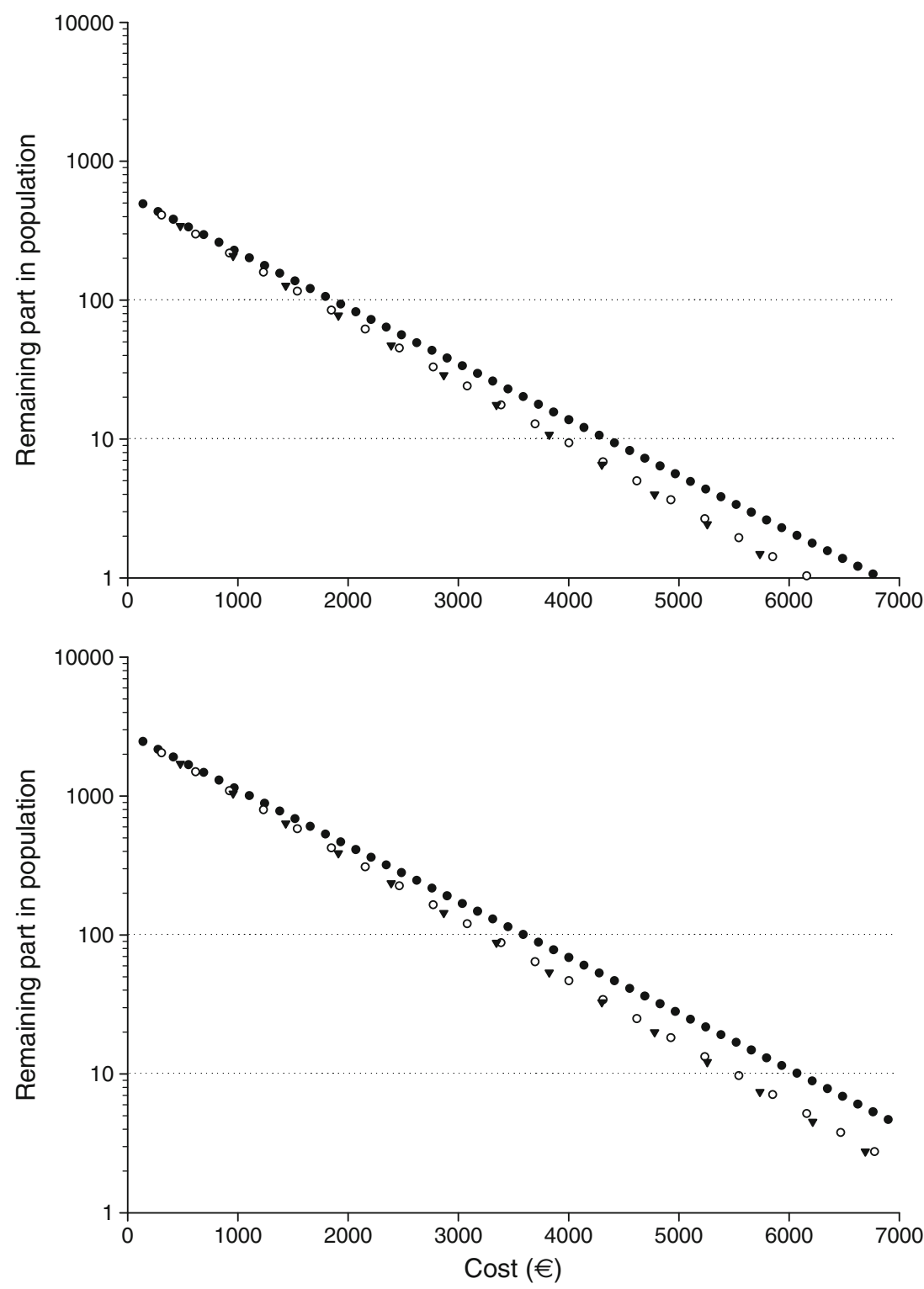

data). Moreover, although not quantified to proportions of actual densities, double fyke nets retained a median value of three metamorphs and five adults per pond over the whole sampling campaign. Once removed, these individuals, in addition to the removed tadpole population, cannot take further part in the reproduction.

It is obvious that bullfrog control with double fyke nets will be most suitable in regions where only a limited number of water bodies are colonized, and thus an integral approach is possible. Specific breeding ponds can be targeted for eradication, so that the overall juvenile recruitment in the population will be negatively impacted. Oppositely, in regions where the species is present in many water bodies, application of other management methods will be more appropriate. In such regions, often only a smaller part of reproduction sites can be tackled, hardly generating an effect on the overall population. In these cases control, rather than eradication, of bullfrog populations is the highest feasible method. Habitat restoration of water bodies (biomanipulation, e.g., the introduction of native piscivorous fish such as pike) can here be put forward as a sustainable alternative (Louette 2012).

Acknowledgments This study was performed in the framework of EU Interreg IV A project IVA-VLANED-2.31 "Invasieve exoten in Vlaanderen en Zuid-Nederland-INVEXO". We thank all the volunteers and project collaborators who helped during the several sampling campaigns. Furthermore, we are grateful to the different site owners and involved governments for their constructive support. Jim Casaer and his team, as well as two anonymous reviewers, are thanked for valuable comments on an earlier version of the manuscript. Euthanasia of caught bullfrogs was conducted according to the legal regulations applicable in Belgium. 
Open Access This article is distributed under the terms of the Creative Commons Attribution License which permits any use, distribution, and reproduction in any medium, provided the original author(s) and the source are credited.

\section{References}

Adams MJ, Pearl CA (2007) Problems and opportunities managing invasive bullfrogs: is there any hope? In: Gherardi F (ed) Biological invaders in inland waters: profiles, distribution, and threats. Springer, Dordrecht, pp 679-693

Adams MJ, Pearl CA, Bury RB (2003) Indirect facilitation of an anuran invasion by non-native fishes. Ecol Lett 6:343-351

Berroneau M, Detaint M, Coïc C (2008) Bilan du programme de mise en place d'une stratégie d'éradication de la grenouille taureau Lithobates catesbeianus (Shaw 1802) en Aquitaine (2003-2007) et perspectives. Bull Soc Herpétol France 127:35-45

Biek R, Funk WC, Maxell BA et al (2002) What is missing in amphibian decline research: insights from ecological sensitivity analysis. Conserv Biol 16:728-734

Bottrill MC, Joseph LN, Carwardine J et al (2008) Is conservation triage just smart decision making? Trends Ecol Evol 23:649-654

Bremner A, Park K (2007) Public attitudes to the management of invasive non-native species in Scotland. Biol Conserv 139:306-314

Cecil SG, Just JJ (1979) Survival rate, population density and development of a naturally occurring anuran larvae. Copeia 1979:447453

D'Amore A, Kirby E, McNicholas M (2009) Invasive species shifts ontogenetic resource partitioning and microhabitat use of a threatened native amphibian. Aquat Conserv: Mar Freshw Ecosyst 19:534-541

Detaint M, Coïc C (2006) La grenouille taureau Rana catesbeiana dans le sud-ouest de la France. Premiers résultats du programme de lutte. Bull Soc Herpétol France 177:41-56

Doubledee RA, Muller EB, Nisbet RM (2003) Bullfrogs, disturbance regimes, and the persistence of California red-legged frogs. J Wildl Manage 67:424-438

EC (2008) Towards an EU strategy on invasive species. Communication of the European Commission 789

EC (2011) Our life insurance, our natural capital: an EU biodiversity strategy to 2020. Communication of the European Commission 244

Ficetola GF, Coïc C, Detaint M et al (2007) Pattern of distribution of the American bullfrog Rana catesbeiana in Europe. Biol Invasions 9:767-772

Garner TWJ, Perkins MW, Govindarajulu P et al (2006) The emerging amphibian pathogen Batrachochytrium dendrobatidis globally infects introduced populations of the North American bullfrog, Rana catesbeiana. Biol Lett 2:455-459

Govindarajulu P, Altwegg R, Anholt BR (2005) Matrix model investigation of invasive species control: bullfrogs on Vancouver Island. Ecol Appl 15:2161-2170

Govindarajulu P, Price WS, Anholt BR (2006) Introduced bullfrogs (Rana catesbeiana) in Western Canada: has their ecology diverged? J Herpetol 40:249-260

Hauser CE, McCarthy MA (2009) Streamlining 'search and destroy': cost-effective surveillance for invasive species management. Ecol Lett 12:683-692

Johnson PTJ, McKenzie VJ, Peterson AC et al (2011) Regional decline of an iconic amphibian associated with elevation, land-use change, and invasive species. Conserv Biol 25:556-566

Jooris R (2005) De stierkikker in Vlaanderen: nieuwe inzichten in verspreiding, foerageergedrag en ontwikkeling. Natuur.focus 4:121-127
Kraus F (2009) Alien reptiles and amphibians: a scientific compendium and analysis. Springer, Dordrecht

Krebs CJ (1989) Ecological methodology. Harper \& Row, New York

Kupferberg SJ (1997) Bullfrog (Rana catesbeiana) invasion of a California River: the role of larval competition. Ecology 78:1736-1751

Lampo M, Bayliss P (1996) Density estimates of cane toads from native populations based on mark-recapture data. Wildl Res 23:305-315

Louette G (2012) Use of a native predator for the control of an invasive amphibian. Wildl Res 39:271-278

Louette G, Declerck S (2006) Assessment and control of nonindigenous brown bullhead Ameiurus nebulosus populations using fyke nets in shallow ponds. J Fish Biol 68:522-531

Lowe SJ, Browne M, Boudjelas S et al (2000) 100 of the world's worst invasive alien species. IUCN/SSC Invasive Species Specialist Group, Auckland

Maceina MJ, Wrenn WB, Lowery DR (1995) Estimating harvestable largemouth bass abundance in a reservoir with an electrofishing catch depletion technique. North Am J Fish Manage 15:103-109

Maret TJ, Snyder JD, Collins JP (2006) Altered drying regime controls distribution of endangered salamanders and introduced predators. Biol Conserv 127:129-138

Martel A, Adriaensen C, Sharifian-Fard M et al (2012) The novel 'Candidatus Amphibiichlamydia ranarum' is highly prevalent in invasive exotic bullfrogs (Lithobates catesbeianus). Environ Microbiol Rep. doi:10.1111/j.1758-2229.2012.00359.x

Moissonnier T, Pérez V, Berroneau M et al. (2007) Programme pluriannuel de mise en place d'une éradication de la grenouille taureau. FDAAPPMA de la Gironde \& Cistude Nature

Mooney HA, Hobbs RJ (2000) Invasive species in a changing world. Island, Washington

Odenkirk J, Smith S (2005) Single-versus multiple-pass boat electrofishing for assessing smallmouth bass populations in Virginia rivers. N Am J Fish Manage 25:717-724

Pearl CA, Adams MJ, Bury RB et al (2004) Asymmetrical effects of introduced bullfrogs (Rana catesbeiana) on native ranid frogs in Oregon. Copeia 2004:11-20

Penczak T, Agostinho AA, Latini JD (2003) Rotenone calibration of fish density and biomass in a tropical stream sampled by two removal methods. Hydrobiologia 510:23-38

Provenzano SE, Boone MD (2009) Effects of density on metamorphosis of bullfrogs in a single season. J Herpetol 43:49-54

Reinhardt F, Herle M, Bastiansen F et al (2003) Economic impact of the spread of alien species in Germany. J.W. Goethe-University, Frankfurt/Main

Rider SJ, Maceina MJ, Lowery DR (1994) Comparisons of cove rotenone and electrofishing catch-depletion estimates to determine abundance of age- 0 largemouth bass in unvegetated and vegetated areas. J Freshw Ecol 9:19-27

Scalera R (2010) How much is Europe spending on invasive alien species? Biol Invasions 12:173-177

Sharifian-Fard M, Pasmans F, Adriaensen C et al (2011) Ranavirosis in invasive bullfrogs, Belgium. Emerg Infect Dis 17:2371-2372

Smith GC, Henderson IS, Robertson PA (2005) A model of ruddy duck Oxyura jamaicensis eradication for the UK. J Appl Ecol 42:546-555

Snow NP, Witmer GW (2011) A field evaluation of a trap for invasive American bullfrogs. Pac Conserv Biol 17:285-291

Szuroczki D, Richardson JML (2011) Palatability of the larvae of three species of Lithobates. Herpetologica 67:213-221

Wassersug RJ (1997) Assessing and controlling amphibian populations from the larval perspective. In: Green DM (ed) Amphibians in decline: Canadian studies of a global problem. Society for the study of amphibians and reptiles, Saint Louis, pp 271-281

Werner EE (1994) Ontogenetic scaling of competitive relations: sizedependent effects and responses in two anuran larvae. Ecology 75:197-213 